\title{
Differences in the Location and Multiplicity of Mandibular Fractures in Kuwait, Canada and Finland during the 1990s
}

\author{
Kyosti Oikarinena, e Lukman Thalib ${ }^{b}$ George K.B. Sàndor ${ }^{d}$ Petr Schutz $^{c}$ \\ Cameron M.L. Clokie ${ }^{d}$ Slavek Safar ${ }^{c}$ Tina Meisamid $^{d}$ Ulla Perheentupa ${ }^{e}$ \\ aDepartment of Surgical Sciences, Faculty of Dentistry, and b Department of Community Medicine and \\ Behavioral Sciences, Faculty of Medicine, Kuwait University, and 'Maxillofacial Surgery Unit, Dental Center, \\ Amiri Hospital, Kuwait; ${ }^{\mathrm{d}}$ Toronto General Hospital, Toronto, Canada; eInstitute of Dentistry, University of Oulu and \\ Oulu University Hospital, Oulu, Finland
}

\author{
Key Words \\ Mandibular fractures - Kuwait · Canada · Finland
}

\begin{abstract}
Objective: To compare the location and multiplicity of mandibular fractures in Kuwait, Canada and Finland during the 1990s. Subjects and Methods: Data were collected from several hospitals in Kuwait (1991-2000), Toronto General Hospital in Canada (1995-2000) and Oulu University Hospital in Finland (1990-1999). The data were analyzed statistically using chi-square test, ANOVA, t test and logistic regression. Results: Condylar fractures were more common in Finnish patients (41\%) than Canadian (35\%) or Kuwaiti patients (21\%). Condylar fractures caused by falls were about 3.4 times more common in Kuwait and Finland compared to Canada. In Finland the risk of road traffic accidents caused by condylar fracture was about 4 times higher than those caused by other etiologies. In Canada male gender was about 2 times higher for the condylar fracture than female gender. Female patients often had more multiple injuries than men in all three countries and multiple fractures were observed especially in traumas caused by falling.
\end{abstract}

Conclusion: Differences in location and multiplicity of mandibular fractures are due to differences in etiologies and demographic patterns.

Copyright $@ 2005$ S. Karger AG, Basel

\section{Introduction}

The majority of mandibular fractures are single fractures and the most frequent location of fracture is the condyle. The second most frequent locations are mandibular angle and symphysis. These regions of third molars and canines are 'weak points' of the lower jaw [1-5].

Location, severity and multiplicity of facial injuries depend much on the age of the victim and on the mechanism of trauma $[1,3]$. Younger patients tend to sustain fractures in the middle third of the face more often than older victims [4-10]. Assault causes unilateral condylar fractures and mandibular angle fractures while falling on the ground causes uni- or bilateral condylar fractures [1] as exemplified in cycling accidents where the chin is often hit on the ground [11]. Traffic accidents cause multiple traumas due to high energetic impacts. During the last 10 years injuries caused by traffic accidents have, however,

\section{KARGER \\ Fax +4161306 1234 \\ E-Mail karger@karger.ch \\ www. karger.com

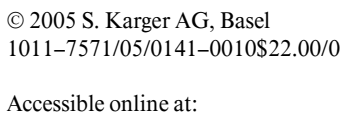

Kyösti Oikarinen

Institute of Dentistry

PO Box 5281, Oulu University

FI-90014 Oulu (Finland)

Tel. +35885375442, Fax +35885375560, E-Mail kyosti.oikarinen@oulu.fi 
Fig. 1. Location of mandibular fractures and percentages of patients with fractures in the given location in Kuwait, Finland and Canada in the 1990s.

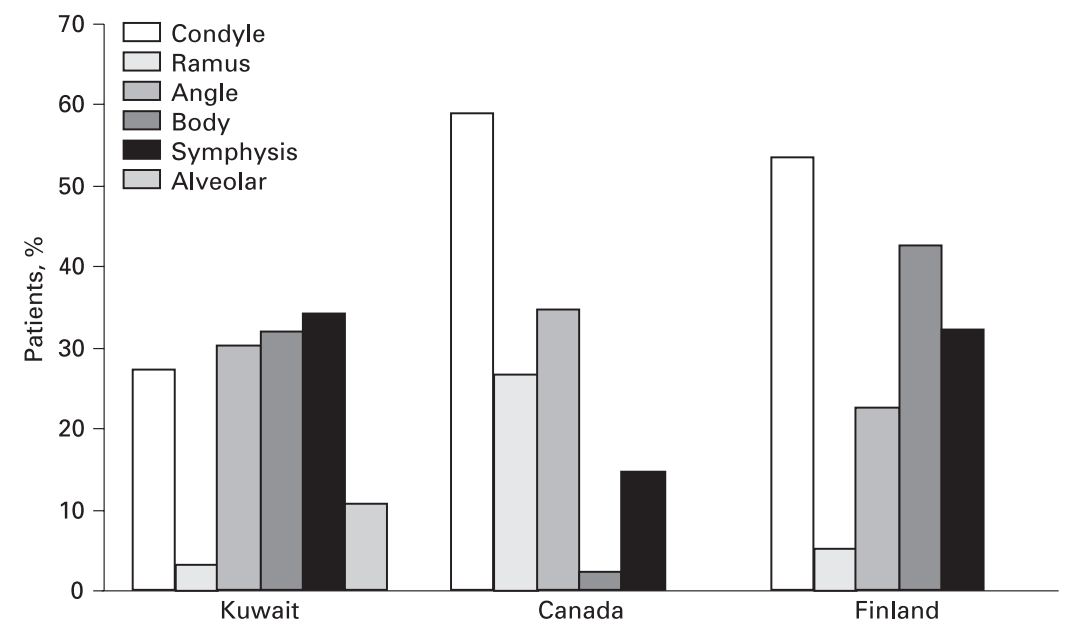

become less severe due to implementation of strict traffic safety rules and measures [12-15].

Most reports on mandibular fractures are national surveys [16-20] and to our knowledge there are no comparative studies that explore the differences in the type and multiplicity of lower jaw fractures in patients from different regions of the globe. This study, therefore, reports the differences in location and multiplicity of fractures from three different countries.

\section{Material and Methods}

The data were collected from several hospitals in Kuwait, Toronto General Hospital in Canada and Oulu University Hospital in Finland. Injuries took place in the 1990s, between 1991 and 2000 in Kuwait, 1995 and 2000 in Canada and 1990 and 1999 in Finland. Etiological aspects of fractures have been reported in separate studies $[16,21,22]$. The data collected were based on patient records and radiographs. In Kuwait the data were collected prospectively by 2 authors (P.S., S.S.). In Kuwait the patient files do not include radiographs as they are possessed by the patients themselves. The diagnosis in Kuwait was thus based on clinical judgment and skull radiographs but not always on panoramic radiographs.

Data in each country were collected consecutively on mandibular trauma patients. Oulu University Hospital served a population of 350,000 . The population of Kuwait in the 1990s varied between 1.5 and 2.0 million inhabitants and the data collected there represented all mandibular trauma cases. The data from Toronto General Hospital is not representative of the entire area as several other hospitals treat trauma patients.

The location of fractures was evaluated using radiographs available. In Kuwait panoramic radiographs were not always at hand but the diagnosis was made clinically or with other methods such as computed tomography or skull radiographic views. The locations were divided into condylar region, ramus, angle, body and symphyseal regions. In Kuwait mandibular alveolar fractures were also included in the analysis.

Etiologies were grouped into five categories: road traffic accident (RTA), falls, violence, sports and other causes. Violence category describes interpersonal fights and falls included both falls on the ground and falls from the height.

Statistical analyses were carried out using SPSS for Windows, version 10.0 (SPSS Inc., USA). Associations between categorical variables were compared between groups, using chi-square test of independence or test of proportion as appropriate. Mean age between groups was compared using ANOVA or $t$ test as appropriate. Further analyses on factors associated with single or multiple fractures and location of injury were carried out using chi-square test and logistic regression. Odds ratios and confidence interval were reported. As the demographic and clinical characteristics varied with countries we have carried out logistic regression separately for each country. Probability levels of $\mathrm{p}<0.05$ were taken as the cutoff to determine the statistical significance and a $p<0.10$ was taken to indicate marginal significance.

\section{Results}

Altogether 818 fractures on 596 patients were registered in Kuwait, 317 fractures on 228 patients in Canada and 417 fractures on 268 patients in Finland. The mean age $( \pm$ SD) of the patients in Kuwait, Canada and Finland were $26.2( \pm 13.8), 31.7( \pm 13.7)$ and $30.7( \pm 12.2)$ years, respectively. 
Table 1. Number of patients, percentual distribution of fracture locations and total number of fractures in male and female mandibular trauma patients in Kuwait, Canada and Finland during 1990-2000

\begin{tabular}{|c|c|c|c|c|c|c|c|c|c|c|c|c|c|c|}
\hline \multirow[t]{3}{*}{ Location } & \multicolumn{7}{|c|}{ Male } & \multicolumn{7}{|c|}{ Female } \\
\hline & \multicolumn{2}{|c|}{ Kuwait $(n=516)$} & \multicolumn{2}{|c|}{ Finland $(n=195)$} & \multicolumn{2}{|c|}{ Canada $(n=190)$} & \multirow[t]{2}{*}{$\mathrm{p}$ value } & \multicolumn{2}{|c|}{ Kuwait $(\mathrm{n}=80)$} & \multicolumn{2}{|c|}{ Finland $(\mathrm{n}=73)$} & \multicolumn{2}{|c|}{ Canada $(n=38)$} & \multirow[t]{2}{*}{$\mathrm{p}$ value } \\
\hline & $\mathrm{n}$ & $\%$ & $\mathrm{n}$ & $\%$ & $\mathrm{n}$ & $\%$ & & $\mathrm{n}$ & $\%$ & $\mathrm{n}$ & $\%$ & $\mathrm{n}$ & $\%$ & \\
\hline Condyle & 140 & 27.1 & 95 & 48.7 & 122 & 64.2 & $<0.001$ & 22 & 27.5 & 48 & 65.8 & 14 & 36.8 & $<0.001$ \\
\hline Angle & 161 & 31.2 & 46 & 23.6 & 65 & 34.2 & $<0.10$ & 19 & 23.8 & 14 & 19.2 & 15 & 39.5 & $<0.10$ \\
\hline Body & 164 & 31.8 & 82 & 42.1 & 3 & 1.6 & $<0.001$ & 26 & 32.5 & 32 & 43.8 & 2 & 5.3 & $<0.001$ \\
\hline Anterior & 173 & 33.5 & 67 & 34.4 & 22 & 11.5 & $<0.001$ & 31 & 38.8 & 19 & 26.0 & 12 & 31.6 & NS \\
\hline Ramus & 17 & 3.3 & 11 & 5.6 & 44 & 23.2 & $<0.001$ & 2 & 2.5 & 3 & 4.1 & 18 & 47.4 & $<0.001$ \\
\hline Alveolar & 53 & 10.3 & - & - & - & - & - & 10 & 15.9 & - & - & - & - & - \\
\hline
\end{tabular}

Total number of

fractures $^{1} \quad 708$

301

256

110

116

61

Each patient could have one or more fractures.

Table 2. Mean age in years $\pm \mathrm{SD}$ of the patient with mandibular fracture in various anatomic locations in Kuwait, Finland and Canada

\begin{tabular}{llllc}
\hline Fractures & Kuwait $(\mathrm{n}=596)$ & Finland $(\mathrm{n}=268)$ & Canada $(\mathrm{n}=228)$ & $\mathrm{p}$ value \\
\hline Condyle & $22.9 \pm 13.6(162)$ & $33.2 \pm 13.8(143)$ & $29.9 \pm 11.9(136)$ & $<0.001$ \\
Ramus & $35.1 \pm 9.4(19)$ & $32.6 \pm 14.1(14)$ & $36.3 \pm 16.2(62)$ & $\mathrm{NS}$ \\
Angle & $25.6 \pm 11.4(180)$ & $27.7 \pm 11.2(60)$ & $31.6 \pm 14.6(80)$ & $<0.01$ \\
Body & $26.9 \pm 13.0(190)$ & $33.5 \pm 15.0(114)$ & $28.5 \pm 13.4(5)$ & $<0.001$ \\
Anterior & $25.8 \pm 13.3(204)$ & $34.2 \pm 13.1(86)$ & $34.2 \pm 13.6(34)$ & $<0.001$ \\
\hline
\end{tabular}

The total number of cases in each category is given in parentheses. Each patient could have one or more fractures.
The mean number of fractures per patient was highest in Finland (1.6) followed by Canada (1.4) and Kuwait (1.4). Mandibular fractures were more often located in the condylar region in Canada and Finland than in Kuwait. The difference in fracture location between three countries was statistically significant in all anatomic locations $(p<0.01)$. Less fractures in the body but more in the angle of the mandible were observed in Canada than in Kuwait or Finland (fig. 1).

For the male, 64.2, 48.7 and 27.1\% of Canadian, Finnish and Kuwaiti patients, respectively, had fractures in the condylar region $(\mathrm{p}<0.001$, table 1$)$. For the female it was 36.8, 65.8 and $27.5 \%$ of Canadian, Finnish and Kuwaiti patients, respectively $(\mathrm{p}<0.001)$. Except for symphyseal fractures in females, all other anatomic locations differed statistically significantly in both sexes in the three countries (table 1).

The mean age ( $22.9 \pm 13.6$ years) of the patients with condylar fractures in Kuwait was lowest while the mean age (35.1 \pm 9.4 years) of those with ramus fractures was highest in Kuwait. In Finland the lowest mean age (27.7 \pm 11.2 years) was among those victims who had angular fracture and highest (34.2 \pm 13.1 years) among those who had symphyseal fractures. In Canada the lowest age (28.5 \pm 13.6 years) was observed among patients with body fractures and highest $(36.3 \pm 16.2$ years) among those with ramus fractures (table 2). The data concerning the mean age for alveolar fractures were missing as these were registered only in Kuwait.

In Finland the fractures were more often multiple fractures than in Kuwait or Canada $(\mathrm{p}<0.001)$ while no statistically significant difference was observed between $\mathrm{Ku}-$ wait and Canada ( $p=0.4882$, table 3$)$. There were statistically significant differences in the proportion of multiple fractures between male and female patients in any country. However, in all three countries, females had a higher percentage of multiple fractures than men. 
Table 3. Comparison of simple or multiple fractures in Kuwait, Finland and Canada

\begin{tabular}{|c|c|c|c|c|c|c|c|c|c|}
\hline & Kuwait & Finland & $\mathrm{p}$ value & Kuwait & Canada & $\mathrm{p}$ value & Finland & Canada & $\mathrm{p}$ value \\
\hline One fracture & $374(62.8)$ & $128(47.8)$ & $<0.001$ & $374(62.8)$ & $149(65.4)$ & 0.4882 & $128(47.8)$ & $149(65.4)$ & $<0.001$ \\
\hline$\geq 2$ fractures & $222(37.2)$ & $140(52.2)$ & $<0.001$ & $222(37.2)$ & 79 (34.6) & NS & $140(52.2)$ & 79 (34.6) & $<0.001$ \\
\hline
\end{tabular}

Table 4. Factors associated with single versus multiple fracture status in each country

\begin{tabular}{|c|c|c|c|c|c|c|c|c|c|}
\hline \multirow[t]{2}{*}{ Variable } & \multicolumn{3}{|c|}{ Kuwait } & \multicolumn{3}{|c|}{ Finland } & \multicolumn{3}{|c|}{ Canada } \\
\hline & OR & $95 \% \mathrm{CI}$ & $\mathrm{p}$ value & OR & $95 \% \mathrm{CI}$ & $\mathrm{p}$ value & OR & $95 \% \mathrm{CI}$ & $\mathrm{p}$ value \\
\hline RTA & 1.98 & $0.92-4.27$ & NS & 0.84 & $0.32-2.18$ & NS & 1.10 & $0.21-5.72$ & NS \\
\hline Violence & 2.38 & $0.99-5.72$ & NS & 0.95 & $0.38-2.39$ & NS & 1.34 & $0.36-4.94$ & NS \\
\hline Sports & 1.32 & $0.40-4.41$ & NS & 0.50 & $0.12-2.09$ & NS & 0.69 & $0.14-3.51$ & NS \\
\hline Falls & 3.59 & $1.59-8.11$ & $<0.01$ & 0.77 & $0.27-2.19$ & NS & 1.63 & $0.43-6.19$ & NS \\
\hline Age $<20$ years & 0.84 & $0.47-1.51$ & NS & 1.73 & $0.81-3.72$ & NS & 1.03 & $0.41-2.57$ & NS \\
\hline $20-30$ years & 1.07 & $0.59-1.95$ & NS & 1.41 & $0.70-2.84$ & NS & 0.98 & $0.44-2.22$ & NS \\
\hline $31-40$ years & 1.16 & $0.60-2.22$ & NS & 1.60 & $0.78-3.28$ & NS & 1.33 & $0.58-3.07$ & NS \\
\hline Male & 0.99 & $0.59-1.66$ & NS & 0.95 & $0.54-1.70$ & NS & 0.84 & $0.35-1.99$ & NS \\
\hline
\end{tabular}

Table 5. Factors associated with subcondylar, condylar neck and/or intracapsular fractures

\begin{tabular}{|c|c|c|c|c|c|c|c|c|c|}
\hline \multirow[t]{2}{*}{ Variable } & \multicolumn{3}{|c|}{ Kuwait } & \multicolumn{3}{|c|}{ Finland } & \multicolumn{3}{|c|}{ Canada } \\
\hline & OR & $95 \% \mathrm{CI}$ & $\mathrm{p}$ value & OR & $95 \% \mathrm{CI}$ & $\mathrm{p}$ value & OR & $95 \% \mathrm{CI}$ & $\mathrm{p}$ value \\
\hline RTA & 1.73 & $0.69-4.37$ & NS & 4.05 & $1.45-11.31$ & $<0.01$ & 0.66 & $0.14-3.24$ & NS \\
\hline Violence & 1.09 & $0.37-3.24$ & NS & 1.66 & $0.62-4.42$ & NS & 1.50 & $0.42-5.30$ & NS \\
\hline Sports & 0.58 & $0.13-2.65$ & NS & 1.15 & $0.24-5.52$ & NS & 0.69 & $0.16-2.96$ & NS \\
\hline Falls & 3.41 & $1.31-8.92$ & $<0.01$ & 3.43 & $1.13-10.46$ & $<0.05$ & 0.48 & $0.13-1.76$ & NS \\
\hline Age $<20$ years & 1.70 & $0.87-3.29$ & NS & 1.05 & $0.48-2.31$ & NS & 0.94 & $0.39-2.28$ & NS \\
\hline $20-30$ years & 1.50 & $0.76-2.98$ & NS & 0.82 & $0.40-1.71$ & NS & 2.00 & $0.88-4.57$ & NS \\
\hline $31-40$ years & 1.02 & $0.48-2.18$ & NS & 1.70 & $0.81-3.60$ & NS & 1.28 & $0.55-2.98$ & NS \\
\hline Male & 1.19 & $0.68-2.09$ & NS & 0.62 & $0.34-1.14$ & NS & 2.20 & $0.91-5.35$ & $<0.10$ \\
\hline
\end{tabular}

Based on logistic regression analysis falls in Kuwait had a risk factor of 3.6 times, more than any other accident that resulted in multiple fractures $(p<0.01)$. Violence in Kuwait resulted in multiple fractures with 2.4 times higher risk than other etiologies (95\% CI 0.99-5.72, table 4). Logistic regression also showed that falls both in Kuwait and Finland caused condylar fractures with an increased risk of 3.4 times compared to Canada. In Finland the risk of RTAs that caused condylar fracture was 4.1 times higher than in those caused by other etiologies
(95\% CI 1.45-11.31). In Canada males had 2.2 times higher in risk for condylar fracture than females $(95 \%$ CI $0.91-5.35$, table 5).

\section{Discussion}

The data from Kuwait and Finland represented a particular geographic area while those from Canada represented only patients treated at the Toronto General Hos- 
pital. Oulu University Hospital treats practically every facial trauma patient in an area covering a population of 350,000 inhabitants. Data in Kuwait were collected by 2 authors who included all mandibular traumas occurring in any of the 22 governmental hospitals in the State of Kuwait. The population of Kuwait in 1997 was 1.8 million.

In Toronto the number of RTAs was small because Toronto General Hospital is not the primary trauma unit in the city. This might also explain the smaller number of multiple traumas in Toronto than in Finland. Traffic accidents in particular cause more severe and more widespread injuries than any other etiologic cause [1]. This is why the results of this study should be interpreted with caution.

The differences in the number and location of fractures can be explained by variation in etiology of accident and age of the patients. The fact that more condylar fractures were diagnosed in Canada and Finland than in Kuwait might be due to lack of availability of suitable radiographs for the diagnosis. Thus the number of condylar fractures in Kuwait could have been underestimated. Even though these cases were collected from three different countries, the evaluation of anatomic location is reliable and comparable because the location of fractures was based on frequently used classification and all diagnoses were done by specialists in oral and maxillofacial surgery.

The low frequency of body fractures in Kuwait is explained by the fact that some of these fractures might have been listed as angular or ramus fractures. The distribution of symphyseal and condylar fractures, however, should be regarded as being more reliable.

The fact that male patients in Canada had more condylar fractures than their female counterparts is explained by injuries in males being caused more often by violence. Hitting the face with a fist usually causes condylar fractures and angular fractures $[1,4,16]$.

In general mandibular fractures occurred in younger Kuwaiti patients than in Finland or Canada. This might be due to the high number of RTAs in Kuwait that involved young patients [21].

The fact that more multiple fractures were registered in Finland than in Kuwait or Canada might be due to the low number of RTAs recorded in Canada, low mean age of the patients and unavailability of multiple radiographs in Kuwait. No gender difference was observed in the frequency of multiple or single fractures. However, the percentage of severe injuries was higher in females than in males. This should be of concern in every country especially as they are due to high numbers of RTAs.
Falls in Kuwait are mostly the result of occupational hazards [21,22]. This should be a national concern. During construction of high-risk buildings attention should be paid to prevention of all occupational injuries. Most falls in Kuwait were from heights. Falls also resulted in multiple injuries more often than did other causes. This illustrates that these accidents involve high-energetic impacts.

We recommend that the results in this study should be taken into consideration when planning future measurements in prevention of mandibular traumas. The fact that female victims suffered severe fractures more frequently than male victims should be a source concern in both traffic safety and prevention of domestic violence. Attention to the use of restraining devices in future legislation might help to prevent serious road traffic injuries. Falls causing more severe injuries should be taken seriously when planning safety measures in construction environment especially in Kuwait.

\section{Conclusions}

The differences in location and multiplicity of mandibular fractures are due to differences in etiologies with falls causing more fractures in Kuwait and Finland than in Canada and female patients suffering severe fractures more frequently than male patients.

\section{Acknowledgments}

This study was supported by the Kuwait University Research Administration Grant No. DS 01/01. $\overline{\text { Med Princ Pract 2005;14:10-15 }}$
Oikarinen/Thalib/Sàndor/Schutz/Clokie/ Safar/Meisami/Perheentupa 


\section{References}

$\checkmark 1$ Iida S, Matsuya T: Paediatric maxillofacial fractures: Their aetiological characters and fracture patterns. J Craniomaxillofac Surg 2002;30:237-248.

$\checkmark 2$ Andersson L, Hultin M, Nordenram A, Ramstrom G: Jaw fractures in the county of Stockholm (1978-1980). I. General survey. Int J Oral Surg 1984;13:194-199.

-3 Andersson L, Hultin M, Kjellman O, Nordenram A, Ramstrom G: Jaw fractures in the county of Stockholm (1978-1980): Jaw fractures in children and adolescents. Swed Dent J 1989; 13:201-207.

-4 Oikarinen K, Kauppi H, Altonen M, Laitakari $\mathrm{K}$ : Causes and types of mandibular fractures in northern Finland 1980-1986. Proc Finn Dent Soc 1988;84:227-233.

$\checkmark 5$ Meisami T, Sojat A, Sàndor GKB, Lawrence $\mathrm{H}$, Clokie CML: Impacted third molars and risks of angle fracture. Int $\mathrm{J}$ Oral Maxillofac Surg 2002;31:140-144.

6 Zerfowski M, Bremerich A: Facial trauma in children and adolescents. Clin Oral Invest 1998;2:120-124.

7 Myall RWT, Sàndor GKB, Gregory CEB: Are you overlooking fractures of the mandibular condyle? Paediatrics 1987;79:639-641.
8 Anderson PJ: Fractures of the facial skeleton in children. Injury 1995;26:47-50.

9 Ellis E 3rd, Moos KF, El-Attar A: Ten years of mandibular fractures: An analysis of 2137 cases. Oral Surg Oral Med Oral Pathol 1985;59: 120-129.

10 Carlin CB, Ruff G, Mansfeld CP, Clinton MS: Facial fractures and related injuries: A ten-year retrospective analysis. $\mathrm{J}$ Craniomaxillofac Trauma 1998;4:44-48.

11 Lindqvist C, Sorsa S, Hyrkas T, Santavirta S: Maxillofacial fractures sustained in bicycle accidents. Int J Oral Maxillofac Surg 1986;15:1218.

12 Kahnberg KE, Gothberg KA: Le Fort fractures (I): A study frequency, etiology and treatment. Int J Oral Maxillofac Surg 1987;16:154-159.

13 Van Beek GJ, Merkx CA: Changes in the pattern of fractures of the maxillofacial skeleton. Int J Oral Maxillofac Surg 1999;28:424-428.

14 Roccia F, Servadio F, Gerbino G: Maxillofacial fractures following airbag deployment. J Craniomaxillofac Surg 1999;27:335-338.

15 Major MS, MacGregor A, Bumpous JM: Patterns of maxillofacial injuries as a function of automobile restrain use. Laryngoscope 2000; 110:608-611.

-16 Sojat AJ, Meisami T, Sàndor GKB , Clokie CML: The epidemiology of mandibular fractures: A review of 246 cases. J Can Dent Assoc 2001;67:640-644.
17 Strom C, Hultin M, Nordenram A, Ramstrom G: Jaw fractures in Stockholm 1988-1990: Changing trends in injury dynamics over a 10 year interval. Swed Dent J 1996;20:221-226.

18 van Hoof RF, Merkx CA, Stekelenberg EC: The different patterns of fractures of the facial skeleton in four European countries. Int J Oral Surg 1977;6:3-11.

19 Bataineh AB: Etiology and incidence of maxillofacial fractures in the north of Jordan. Oral Surg Oral Med Oral Pathol Oral Radiol Endod 1998;86:31-35.

20 Oikarinen K, Ignatius E, Kauppi H, Silvennoinen U: Mandibular fractures in Northern Finland in the 1980's: A 10 year study. Br J Oral Maxillofac Surg 1993;31:23-27.

21 Oikarinen K, Schutz P, Lukman T, Sandor GKB, Clokie C, Meisami T, Slafar S, Moilanen M, Belal M: Differences in the etiology of mandibular fractures in Kuwait, Canada and Finland. Dent Traumatol 2004;20:241-245.

22 Schutz P, Safar S, Al-Yassin SM, Belal MS, Korinek P: Maxillofacial fractures in Kuwait between 1992-1997. Asian J Oral Maxillofac Surg 2001;13:195-201. 